\title{
Use Them but Do Not Abuse Them
}

\author{
Alex Atock* \\ 10 Fishermans Reach, UK \\ *Corresponding author: Alex Atock, 10 Fishermans Reach, Wilton, Ross-on-Wye, UK. \\ To Cite This Article: Alex Atock. Use Them but Do Not Abuse Them. Am J Biomed Sci \& Res. 2019 - 4(2). AJBSR.MS.ID.000764. \\ DOI: 10.34297/AJBSR.2019.04.000764
}

Received: May 13, 2019 | Published: July 18, 2019

\section{Commentary}

The origin of the partnership between man and horse goes back to prehistory. There is evidence of this partnership in the art and literature of ancient China, Egypt, Persia and Greece. Xenophon wrote "The Art of Riding" 2000 years ago. The horse played its part in peace and in war. It was used for practical purposes in agriculture, hunting and transport and it was also used for recreation and sport. Most of the sports were purely local and depended on the culture and traditions of each community. Some of these sports were based on military skills, others were derived from hunting, but it is probable that wherever horses were used some form of racing will have taken place.

Equestrian sports as we know them to-day, particularly the Olympic disciplines of jumping, dressage and eventing were born in the middle of the 19th century. The Sociéte Hippique Francaise was founded in 1865 and a year later it organised its first Concours Hippique (Horse Show). This led to the first organised national "circuit" of such Concours. In July 1868 the Royal Dublin Society (RDS) included in the program of its annual "Horse Show", for the first time, two jumping competitions: the "high leap" and the "wide leap", both derived from the Irish passion for fox hunting. The Irish Times, reported on 31st July 1868 that the "high leap" fence was raised to six feet, which was jumped in magnificent style by Richard Flynn's Shaun Rhue, to whom first prize of $€ 10$ (approximately US\$12/13 in to-day's money) was awarded. Fast forward to May 1921 when a meeting took place in Lausanne in Switzerland, chaired by the President of the International Olympic Committee, Baron de Coubertin, with representatives of ten nations present. Representatives of four of these nations, United States, France, Japan and Sweden proposed the constitution of an International Equestrian Federation (FEI) which was accepted by the other six. (Courtesy Max E. Ammann, History of International Equestrian Sport, Bern, Switzerland. Federation Equestre Internationale, printed in Switzerland 12/1989). Since then, all international events, taking place in FEI member countries, come under the auspices of this governing body.

It can be a major problem to keep horses healthy and sound. The dividing line between the treatment of injury and disease on one hand and the preparation of horses for competition on the other is narrow and not easily defined. It is obviously correct to use medication to cure injury and disease but patently wrong to use drugs to influence performance or to enable an unfit or unhealthy horse to return to competition before it has fully recovered. It is accepted that the commercial aspect of the sport places great demands on those responsible to compete with their horses to the best of their ability, often more frequently than they should. This places the competitor and his veterinarian in an unenviable position. A practical solution must be found to balance the everincreasing sophisticated analytical methodology and the practical day to day requirements of the equine athletes. The days when horses raced on hay, oats and water, long before dressage, jumping and international rules ever existed, probably terminated in biblical times. This was when Adam and Eve ate the forbidden fruit. They did so, not because they were hungry, but because the serpent deceived them into believing that the fruit would render them God-like. Folklore and fairy tales are full of the belief that magical substances exist, capable of imparting supernatural powers.

Think of Popeye the sailor, who supposedly obtained enormous strength and ability from eating spinach. Think of the early Romans who fed their chariot horses a mixture of honey and water and suffered crucifixion when caught. It is generally accepted that equines benefit from their association with man. Their use is beneficial. Their abuse is not. Similarly, stress is largely beneficial, but distress is to be avoided. The welfare of all animals has become increasingly topical over the years. This varies from public rejection of animal experimentation, through factory farming, to the stresses imposed by long journeys, often under deplorable conditions with little, if any, food and water which many horses (and other animals) must endure on their final travels mostly from Eastern Europe, or from South America, to the slaughter houses in Belgium, France and Italy and from North America to Canada or Mexico. There is no problem in eating horse meat to meet the demand but there can be little justification for not slaughtering them (and other animals) close to home and so avoid these horrendous journeys. It would be infinitely preferable to have them transported "on the hook" 
rather than "on the hoof". In saying this we must always remember the hugely varied culture between countries. Religions, history, tribal rivalries, acute poverty and extreme wealth can all influence attitudes to animals and in some countries the concept of 'animal rights' or even 'animal welfare' may not be recognised.

In the sport horse world, both in racing and in the competition arena, the specialist equestrian press publishes what it sees. It is up to us to ensure that what they see is acceptable. A smile and a pat on the neck are infinitely preferable to a scowl and a jab on the reins from a rider following an unsuccessful round. In racing, the sight of a horse being ridden out to obtain maximum placing, encouraged by the jockey's hands and heels and maybe a slap down the shoulder, is surely preferable to the image of whips being used to encourage horses which can be perceived, by the uninitiated, as inflicting pain and fear into the animal.

In conclusion, enjoy your association with your partner, the horse, but always remember to respect him, whether it is in a field at home teaching your child to ride, hunting, competition riding as a beginner or at the highest level and racing through all the different grades. Finally, never forget the masses of horses, mules and donkeys in the impoverished world, who must strive each day to work their hardest, often in extreme heat with little food or water, to put food on the table for their owner and his family each night. Use your horse well and do not abuse him. 